at a level which should prove both helpful and stimulating to the more advanced student who may later specialize in optics.

The first five chapters deal with the general geometrical theory of the perfect image-forming optical system, the paraxial theory of optical instruments, the determination of the constants of optical systems, and the use of the prism in refractometry and spectroscopy. Next, the mathematical treatment of the wave equation, and the ideas of coherence and wave and group velocity, introduce the wave theory of light. Three chapters on interference followtreating the interference of two beams by wave-front division, that of two beams by amplitude division, and multiple-beam interferometry. Chapter 10, after a critical discussion of Fresnel's theory of diffraction, deals fully with Kirchhoff's diffraction formula, and then explains the basis on which diffraction patterns are classified as 'Fresnel' or 'Fraunhofer'. Chapter 11, on the single slit, and Chapter 12, on diffraction gratings, between them cover all aspects of Fraunhofer diffraction. Chapter 13 deals separately with the Fresnel type. It is usual (and indeed essential if they are to be intelligible) to dissect interference and diffraction effects in this manner, but it is rarely so constructively done; and it is a great assistance to find practical applications such as the Twyman-Green interferometer, the wave-front shearer, and the Sears-Barrell length-standard work, classified likewise under the appropriate heading.

Chapters 15 and 16 discuss the aberrations of lenses, the means of controlling them in optical systems, and a number of standard lens combinations. The chapter on visual optics deals also with colour that on photometry is chiefly concerned with standards and with visual photometry. The final chapters deal with the electromagnetic theory, the propagation of light in crystals, optical activity, and the velocity of light. Much has been done since R. T. Birge's review of this last subject in 1941, and a good account of the work up to 1957 is given here.

This last comment summarizes one quite striking feature of the book; that it is the work of an enthusiast who would have his students well informed on current progress. But the whole is unusually well planned for its purpose, from the patient sorting out of the sign convention at the beginning to the arrangement of the severer mathematics for "omission at a first reading"; it is a really excellent book. Dr. Longhurst, in the preface, calls it "a student's textbook". This it most certainly is, but there must be many people well past their student days who will find it to be a valuable work of reference.

G. R. NOAKES

\section{HISTORY OF IRON IN BRITAIN}

History of the British Iron and Steel Industry from C. 450 B.C. to A.D. 1775

By Dr. H. R. Schubert. Pp. xxi $+445+26$ plates. (London: Routledge and Kegan Paul, Ltd., 1957.) $60 s$. net.

TOWARDS the end of the fifteenth century a technological discovery was made which revolutionized the iron industry and was, in fact, the harbinger of our modern civilization. From the very beginning of the Iron Age this metal had been pro- duced by the direct reduction of the ores in furnaces of small size in which the temperature normally never attained that required for fusion, though it is certain that on occasion and by accident the sponge iron produced became carburized to such an extent that a molten product-white cast iron-was obtained. As the size, and particularly the height, of the furnace in which the reduction was effected was increased, higher and higher temperatures were attained until, finally, the forerunner of the modern blast-furnace was developed and molten iron was produced deliberately. This great change in technique resulted in a relatively enormous increase in output. It further provides the justification for the division of this really important contribution to the history of technology into two parts, the first concerned with the early history of a process which resulted in a soft sponge iron, the latter in the production of molten cast iron, used at first mainly for the production of military castings, which required a second process for its conversion into a malleable product.

The author, a professional historian, surveys the whole history of the industry from the first introduction of iron to Britain to the time when molten steel was produced commercially by the Huntsman process; but nowhere is his background shown to better advantage than in the skill with which he has revealed the extent to which the introduction of the blast-furnace increased the output of metal obtained. In the course of a few decades the daily output per furnace was raised some seven times. The wide field over which the material has been collected and the great skill with which it has been sifted and woven into a surprisingly coherent story deserve the highest praise.

Of the earliest English blast-furnaces neither picture, description nor remains have been preserved: the furnace, previously supposed to be of this nature, from a drawing in the Public Record Office, was, in fact, a lead furnace erected in Derbyshire about 1552. It is, therefore, from the accounts of the Sussex ironworks, from 1541 onwards, that it has been possible to obtain some idea of the structure as it existed in the early sixteenth century, and the author has been able to reconstruct the main outlines of this piece of equipment, a description which is rendered the more vivid from the excellent coloured frontispiece of a painting by the Flemish artist, Blès.

There are certain minor imperfections in the text : W. Goland of Appendix 1, for example, should surely be Prof. W. Gowland, and that the author is not himself a metallurgist is here and there apparent. It is this fact, presumably, which leads him to perpetuate the heresy that there was some special virtue or magic in ores containing small amounts of manganese and titanium which rendered it possible for primitive metallurgists to produce a steel, as distinct from soft iron, in the early direct furnace. It is quite easy to do this even in the complete absence of either of those elements by allowing the reduced sponge to remain in contact for a sufficient time with the glowing charcoal.

Despite such blemishes, however, there can be no question that the volume under consideration is one of quite outstanding merit, for which the archæologist and technologist alike owe a very deep debt to the author himself and to the Iron and Steel Institute, through the support of which the researches here recorded were carried out. F. C. THompson 